\title{
Prepositions in Use: Prepositions of Standard, Prepositions of Possession and Prepositions of Accompaniment
}

\author{
Naji Masned AlQbailat \\ Director of the Language Center, Al-Balqa' Applied University, Jordan \\ E-mail: najimq1@bau.edu.jo \\ Islam M. Al-Momani (Corrosponding author) \\ Princess Alia University College, Al-Balqa’ Applied University, Jordan \\ E-mail: almomani_islam@yahoo.com \\ Yazan Shaker Almahameed \\ Ministry of Education, Jordan \\ E-mail: yazan.shaker@yahoo.com
}

\author{
Doi:10.7575/aiac.alls.v.7n.4p.1 \\ URL: http://dx.doi.org/10.7575/aiac.alls.v.7n.4p.1
}

Received: $11 / 02 / 2016$

Accepted: 16/04/2016

\begin{abstract}
The current research paper attempted at investigating the use of prepositions of standard, prepositions of possession and prepositions of accompaniment by some Jordanian learners of English. A total of 53 Jordanian English Majors participated in the study from the department of English language at Princess Alia University College. In collecting the needed data for the purpose of the study, the researchers employed fifteen items of a multiple choice test. The results of the study showed that Jordanian learners of English encountered moderate difficulty in learning the three aforesaid usages of prepositions. This difficulty is ascribed mainly to first language interference more than intralingual interference. It was also found that prepositions of standard are the most difficult to learn by the participants, followed by prepositions of accompaniment and prepositions of possession respectively.
\end{abstract}

Keywords: First language Interference, Intralingual Interference, Prepositions of Standard, Prepositions of Accompaniment, Prepositions of Possession

\section{Introduction}

Many researchers have advanced numerous definitions of prepositions, and one of the most working definitions was presented by Quirk et al. (1985, p.673) who has argued that "A preposition expresses a relation between two entities, one being that represented by the prepositional complement, the other by another part of the sentence". It is obvious from the aforementioned definition that a preposition performs the function of joining two parts of speech, such as joining a noun to a noun, a noun to a verb, a noun to an adjective or a verb to an adjective. Building a relationship between two entities in a sentence by using a preposition is exemplified in the two sentences below.

1- Smith has met his friend in the mall.

2- Maggie is always complaining about hot weather.

In sentence 1, the preposition in joins the noun friend with the noun phrase the mall. Likewise, in sentence 2 , the preposition about relates the verb complain to the adjective hot in order to show the relationship between the two. English language is characterized by having a large number of prepositions. Leacock et al, (2014) states that, there are over one hundred prepositions in English language. Prepositions in English fall into two main types; first, simple prepositions: this type of prepositions is comprised of only one word such as in, on, at, with, by etc. Second, Complex prepositions, these prepositions consist of two words or more combined together as with respect to, in front of, because of and etc (Ballard, 2013). English prepositions can express various meanings in a sentence. As stated by Quirk (1985), these meanings can be varied as the following; spatial meaning, temporal meaning, prepositions of manner and instruments, prepositions of accompaniment, prepositions of support and opposition and prepositions of concession and respect. Prepositions in English can be further used to indicate origin or source, possession, respect, standard and exception. In a similar vein, Arabic prepositions can be utilized to express numerous notions such as time, place, accompaniment, support, source, respect and standard. It is fit to indicate that Arabic language has only twenty simple prepositions (Alayesh, 2012). This research paper places its concern on three meanings of prepositions in English and Arabic namely, prepositions of accompaniment, possession and standard. These three usages are particularly investigated thoroughly in various studies done by some researchers in the Arab world. Other studies have concentrated on the common meanings of prepositions such as temporal and spatial meanings and no studies have examined prepositions of accompaniment, possession, and standard in particular. Before going any further, it is appropriate to illustrate the use of these three meanings of prepositions in English and Arabic with some clarifying examples. 
Prepositions of accompaniment are expressed in English by using the preposition with. Similarly, Arabic uses the preposition ma9 to express the notion of accompaniment. Ma9 in Arabic is correspondent to with in English.

- Rami likes to drink tea with milk.

-yohibu Rami ?an yashraba af-Jaya ma9 alhalibi

In English prepositions of possession are expressed by using on, with and of. Likewise, the preposition bi (by) is used to talk about possession in Arabic as follows;

-The man with the blue shirt is my uncle.

-?1rajulu bi alqameesi ?1?azraqi 9ami.

English language uses the preposition at to talk about the notion of standard, whereas Arabic employs the preposition $f i$, which is similar to in in English.

-Ali is clever at doing brain teasers.

-?ali thakiun fii ?alalqazi.

Based on the above mentioned discussion, the present study seeks to investigate the proficiency of some Jordanian EFL learners in three areas of English prepositions; prepositions of accompaniment, possession and standard.

\section{Literature review}

Researchers around the globe have implemented very huge body of studies on the acquisition of English prepositions by second language learners from various native language backgrounds. However, researches that have been conducted on the use of prepositions by Arab speakers of English are a few (Habash, 1982; Asma, 2010; Almahammed, 2011; AlQudah, 2013).

One of the earliest studies in this area of language was done by Habash (1982) among Palestinian EFL learners studying in Jerusalem province. All the participants were school students, speaking Arabic as native language. The study aimed primarily at determining the sources of prepositional errors made by the respondents. The researcher used a composition test and a multiple choice test as measurement tools. The findings of the study revealed that errors attributed to transfer from Arabic language are the chief source of the faulty usage of English prepositions, accounting for $65,3 \%$ of total errors. The results further showed that errors caused by intralingual interference were $34.7 \%$

Asma (2010) looked at the use of English prepositions by Algerian EFL speakers. The study sought to get insight into the role of transfer from Arabic in the acquisition of English prepositions. The researcher limited the investigation to two usages of prepositions, namely; spatial and temporal prepositions. A fill in blank test was employed to collect the needed data for the study. The researcher has found that Algerian EFL learners were affected by their native language (Arabic). The results additionally reported that the respondents were influenced by their colloquial Arabic and French.

Almahammed (2011) investigated the role of avoidance strategy in the acquisition of English prepositions by Jordanian EFL speakers at Mu'tah University. The study aimed at measuring the construction of prepositions made by the respondents in cases of similarities between English and Arabic prepositions and differences between the two prepositional systems. In a bid to collect the required data, the researcher has utilized three types of instruments; 1multiple choice test, 2- translation test and 3- correction test. The researcher has arrived at the conclusion that Jordanian EFL speakers have resorted to an avoidance behavior in the case of differences between English and Arabic prepositions much more than cases of similarities. These results are explained by the fact that English and Arabic express few meanings in common.

Al-Qudah, (2013) carried out a research study about the acquisition of English prepositions among Jordanian EFL speakers. The scope of the study was restricted to prepositions of time, whereas other meanings of prepositions were excluded. A total of 197 Jordanian EFL learners have taken part in the study. Having analyzed the results of the study, the researcher concluded that the preposition at was found to be the most difficult to acquire by the participants because this preposition showed the highest proportion of errors. In contrast, the preposition until was accepted more readily than all prepositions of time in the study.

In conclusion, it could be said that all the previously mentioned studies have shown that Arab learners of English encounter serious problems in acquiring English prepositions. These problems result from two main sources, either cross-linguistic interference (first language interference) or intralingual interference. This piece of study attempts to look at the difficulties in learning some English prepositions and sources of these difficulties.

\section{Statement of the problem}

Prepositions are one of the most troublesome areas in English language (Cosse, 2005). English language learners all over the world in general and in the Arab countries in particular confront serious difficulties in mastering English prepositions (Tahaineh, 2010; Al-Hassan, 2013). The difficulties that could encounter Arab learners of English result from two primary factors; the first one is resulted from the fact that prepositions in English are much in number. There are over one hundred prepositions in English that make understanding the meanings of such wide range of prepositions a painstaking process. The second factor is due to the fact that differences between English and Arabic prepositions in terms of meanings and forms are very huge, putting learners into a trap of guessing or sometimes failing to get their message through. The significance of this study stems from filling a gap in literature by examining three usages of English prepositions, which are rarely highlighted by previous studies. These three usages are prepositions of accompaniment, prepositions of possession and prepositions of standard.

\section{Objectives of the study}

The present study seeks to accomplish the following two objectives: 
1- Determining the difficulties in the use of prepositions of accompaniment, prepositions of possession, and prepositions of standard.

2- Determining the most problematic usage of English prepositions among the three usages under investigation in this study.

\section{Research questions}

This particular research study attempts at answering two main questions.

1- Are there any difficulties encountering the respondents in their use of prepositions of accompaniment, prepositions of possession and prepositions of standard? If any, what are the sources of these difficulties?

2- Among the three usages of prepositions under investigation in this study, which one is the most problematic to acquire?

\section{Methodology}

6.1 Population of the study

The population of the current study consisted of all Jordanian students majoring in English as a second language at Princess Alia University College in Amman. All the students were females as males are not allowed to join this college.

6.2 Sample of the study

In choosing the sample of the study, the researchers have randomly employed a sample of about fifty three students from first to fourth academic year majoring in English language. Participation in the study was optional; no respondents were forced to be part of the sample. Answers of the participants in the study were kept confidential and only used for the purpose of this research paper.

\subsection{Instrumentation}

With the aim of collecting the requested data for the present study, a multiple choice test was designed. The test was comprised of fifteen sentences. Five sentences were dedicated for each usage of prepositions under investigation. More precisely, five sentences on prepositions of accompaniment, five sentences on prepositions of possession and five sentences on prepositions of standard. The respondents were instructed to select one preposition from among four prepositions provided below each sentence as options.

\section{Results}

This section reports the findings of the study obtained via analyzing the data collected from the participants. This includes the results related to research question number one, and after that, the results of question number two will be presented.

Question one is formulated as the following:

1- Are there any difficulties encountering the respondents in their use of prepositions of accompaniment, prepositions of possession and prepositions of standards? If any, what are the sources of these difficulties?

The results relevant to question one are reported in table 1 below. Table 1 shows the frequency and percentage of errors made by the respondents. In addition, the table reveals the percentage and frequency of incorrect responses.

Table 1. Percentage of correct and incorrect answers

\begin{tabular}{ccc}
\hline Item & Percentage of errors & Percentage of correct answers \\
\hline 1 & $69 \%$ & $31 \%$ \\
\hline 2 & $72 \%$ & $28 \%$ \\
\hline 3 & $75 \%$ & $25 \%$ \\
\hline 4 & $62 \%$ & $38 \%$ \\
\hline 5 & $81 \%$ & $19 \%$ \\
\hline 6 & $13 \%$ & $87 \%$ \\
\hline 7 & $2 \%$ & $98 \%$ \\
\hline 8 & $9 \%$ & $91 \%$ \\
\hline 9 & $19 \%$ & $81 \%$ \\
\hline 10 & $44 \%$ & $56 \%$ \\
\hline 11 & $38 \%$ & $62 \%$ \\
\hline 12 & $13 \%$ & $87 \%$ \\
\hline 13 & $6 \%$ & $94 \%$ \\
\hline 14 & $38 \%$ & $62 \%$ \\
\hline 15 & $32 \%$ & $68 \%$ \\
\hline Grand & $38.2 \%$ & $61.8 \%$ \\
Total & & \\
\hline
\end{tabular}

Based on the results shown in Table 1 above, it is obvious that the total percentage of incorrect answers made by the participants is nearly $38.2 \%$. In contrast, the total percentage of correct answers is about $61.8 \%$. These findings assert that Jordanian students learning English as a second language face difficulties in their use of prepositions of accompaniment, prepositions of possession and prepositions of standard. However these difficulties are too serious but 
at a moderate level since most of the answers supplied by the participants were correct. The second part of question one aimed to ascertain the sources of errors that are made by the participants. It has been agreed that there are two main factors causing errors while learning the second language; cross-linguistic interference (first language interference) and intralingual interference (Gass and Selinker, 2008). Cross-linguistic interference is known as the influence stems from native language in second language situation while intralingual errors are those caused by incomplete learning of the second language. In particular, intralingual errors comprised all types of errors caused by factors other than first language interference. In order to determine the sources of errors in the use of prepositions of accompaniment, prepositions of possession and prepositions of standard, let us consider table 2 below.

Table 2. Intralingual interference and cross-linguistic interference

\begin{tabular}{lc}
\hline Intralingual interference & $17.2 \%$ \\
\hline Cross-linguistic interference & $21 \%$ \\
\hline Correct answers & $61.8 \%$ \\
\hline
\end{tabular}

It is obvious from the table above that the percentage of errors resulting from intralingual interference is $17.2 \%$. Conversely, the percentage of errors stemmed from cross-linguistic interference is $21 \%$. These results indicate that the majority of errors in the use of prepositions of accompaniment, prepositions of possession and prepositions of standard are caused by interference from Arabic (native language for the participants). These results are compatible with the results of a study implemented by Tahaineh (2010) who found that first language interference is the chief factor responsible for errors committed by the participants, where $58 \%$ of errors in the use of English prepositions stemmed from native language interference. Tahaineh's study further revealed that $42 \%$ of errors could be attributed to factors such as intralingual interference. That is to say, two primary factors are influential in the second language situation, namely; first language interference and intralingual interference. The finding of this particular study asserted that first language interference is the major source of errors while learning the three usages of prepositions under investigation. Having revealed the results of question one, results relevant to research question two are displayed below.

Question two was formulated as follows:

2- Among the three usages of prepositions under investigation in this study, which one is the most problematic to master?

The results pertinent to question two are depicted in table 3 below. Table three reveals the percentage of errors for each of the three usages of prepositions; prepositions of accompaniment, prepositions of possession and prepositions of standard.

Table 3. Percentage of errors in the three usages of English prepositions

\begin{tabular}{cc}
\hline Usage of prepositions & Percentage of errors \\
\hline Prepositions of standard & $23.9 \%$ \\
\hline Prepositions of possession & $5.8 .1 \%$ \\
\hline Prepositions of accompaniment & $8.4 \%$ \\
\hline
\end{tabular}

It is clearly indicated in Table 3 above that the percentage of errors committed in the use of prepositions of standard is $23.9 \%$. The percentage of errors made while learning prepositions of possession is $5.8 \%$, while the percentage of incorrect answers in the use of prepositions of accompaniment is $8.4 \%$. It could be inferred from the above mentioned results that prepositions of standard are the most problematic usage to master, followed by prepositions of accompaniment. Prepositions of possession came in the last place in terms of difficulty.

\section{Discussion of results}

The results of the first research question have shown that the respondents face some difficulties in the acquisition of prepositions of accompaniment, prepositions of possession and prepositions of standard. The results revealed that $38.2 \%$ of respondents' answers were incorrect. It was found that most of respondents' errors are ascribed to native language interference. The occurrence of errors due to the influence of the native language rather than intralingual errors can be explained according to the differences between English and Arabic prepositional systems in terms of usages and forms. The example below illustrates theses differences.

$$
\text { - He is always good ------------ reciting the holy Quran }
$$

The blank in the above mentioned sentence must be filled with the preposition at since in English at is normally used to express the notion of standard. However, in Arabic the situation is completely different in which the preposition $f i i$ "in" is the most appropriate to use. Such differences between prepositions in the two languages lead to the erroneous use of English prepositions by Arab learners of English. Furthermore, the results have depicted that prepositions of standard are the most problematic to use for Jordanian learners of English, followed by prepositions of accompaniment and prepositions of possession consecutively. 
It could be said that the high occurrence of errors in the use of prepositions of standard refers to the huge differences between English prepositions and their Arabic counterparts when expressing standard relationship. These differences are exhibited by the fact that English language utilizes the preposition at for the notion of standard, whereas Arabic uses the preposition fii, which is equivalent to in in English language. In addition, the other two usages of prepositions namely; prepositions of accompaniment and prepositions of possession have displayed low level of incorrect responses due to the big similarities between English and Arabic prepositions when talking about accompaniment and possession. In English the idea of accompaniment is expressed via using the preposition with. Likewise, Arabic employs the preposition $\mathrm{ma}$, which is correspondent to with in English to talk about accompaniment relationship. Moreover, in English the prepositions with and of are used to convey the meaning of possession. In a similar vein, in colloquial Arabic the preposition $b i$ "with" is mostly utilized with possession relationship. In brief, differences in use between English and Arabic prepositional systems are the primary factors at work, leading to both native language and intalingual errors.

\section{Conclusion}

The present study has arrived at two chief findings; first Jordanian learners of English encountered moderate difficulty in learning English prepositions. These difficulties can be attributed to first language interference rather than intralingual interference. The findings of the study have further revealed that prepositions of standard posed the greatest difficulty, compared to prepositions of accompaniment and prepositions of possession.

\section{References}

Alayesh, M. (2012). The effect of Arabic prepositions on the use of English prepositions. Managing Knowledge and intellectual capital in Higher Education institutions in Egypt and Arab World. Mansoura University. Pp. $1744-1752$.

Al-Hassan, A. (2013). The effects of Arabic on English writing of Petra University students. Journal of modern education review, 3(3), 256-263.

Al-Qudah, A. Kh. (2013). Acquisition of some selected prepositions of time by English major undergraduates at Balqa Applied University in Jordan. English Language Teaching, 6(9), 97-109.

Al-Mahammed, Y. (2011). The impact of avoidance behavior on learning English prepositions by Jordanian English majors at Mutah University. Master Thesis. Mutah University.

Asma, T. (2010). Transfer of Simple Prepositions from Standard Arabic into English: The Case of Third Year LMD Students of English Language at Mentouri University - Constantine. Unpublished Master thesis, Mentouri University.

Ballard, B. (2013). The Frameworks of English: Introducing Language Structures. USA. Palgrave Macmillan .pp. 44.

Cossé, L. (2005). My communicative grammar: study guide. Venezuela: University of Carabobo.

Habash, Z. (1982). Common errors in the use of English prepositions in the written work of UNRWA students. Master thesis, Birzeit University.

Gass, S \& Selinker, L. (2008). Second language acquisition; an introductory course $3^{\text {rd }}$ ed. USA: Taylor \& Francis group.

Leacock, C. Chodorow, M. Gamon, M and Tetreault, J. (2014). Automated grammatical error detection for language learners. Morgan and Claypool publishers. Pp. 47.

Quirk, R, Greenbaum, S, Leech, G, \& Svartvik, J. (1985). A comprehensive grammar of the English language. London: Longman.

Tahaineh, Y. (2010). A study of Arab EFL University Students' Errors in the Use of Prepositions. MJAL2. Pp 76-112.

\section{Appendix (the research instrument)}

Read the sentences below carefully and then select the appropriate preposition to complete the meaning of each sentence.

1- He is always good ------------ reciting the holy Quran

$$
\text { a- in b- at c-by d-with }
$$

2- Sami is very clever ------------ mathematics

$$
\text { a- from b- in c- on d- at }
$$

3- He is extremely poor ---------- Chemistry

a- in b-on c- at d- to

4- Sara is known for being bad --------- playing chess.

a- at b- for c-to d- in

5- Sameh is remarkably terrible ----------- games.

a- to b-with c- at d- in


6- The president ......... the United States has attended the Independence Day ceremony.
a- with
b- by
c- of
d- in

7- Hamlet is a famous play was written ----------- Shakepeare.
a- in
b- with
c- by
d- of

8- The boy --------- red hair got into the car
a- in
b- at
c- with
d- on

9- The man --------- the blue T-shirt is my uncle Jack.
a- by
b- in
c- on
d- with

10- The vehicle ------------- two tires is a new invented car.
a- in
b- on
c- with
d- by

11- I'm so glad you're coming ---------- us.
a- to
b- from c- of
d- with

12- Rice -------- curry is my favorite dish.
a- at
b- on
c- in
d- with

13- I like spaghetti ---------- white sauce.
a- by
b- at
c- with
d- on

14- Samia went ---------- her husband to a book fair
a- to
b- by
c- with
d- at

15- Salem went for dinner ---------- his apartment mate.
a- by
b- with
c- in
d- of 